\title{
Cuando los economistas son además personas
}

\author{
José Ignacio González Faus \\ Cristianisme i Justícia \\ Barcelona (España)
}

Es ya dato público que el libro de Thomas Piketty, El capital en el siglo XXI (Fondo de Cultura Económica, 2014) ha sido considerado el mejor libro de economía del año 2014, hasta el punto de que fue galardonado con la "Legión de honor" que su autor rechazó, parece que como protesta discreta contra el actual gobierno francés.

El horizonte del libro es la convicción de que el capitalismo lleva actualmente una dinámica que irá produciendo unos pocos ricos cada vez más ricos, y masas de pobres cada vez más pobres. Por otro lado, la economía no es el arte de enriquecerse, sino el estudio de las desigualdades entre los hombres y la búsqueda de remedios para ellas. En los economistas clásicos del XVIII y el XIX, "la distribución era ya el centro de todos sus análisis" (17): la preocupación de todos ellos, no solo de Marx, sino de Malthus, Ricardo y de otros, eran las causas y el remedio de las desigualdades entre los hombres, cosa que han perdido los economistas modernos ${ }^{1}$. Esto quiere expresar el título dado a esta presentación.

De ahí concluye el autor que la economía no puede ser una ciencia endogámica, sino muy relacionada con otros factores: la historia, la política y todas las demás ciencias sociales. Avisa por eso honradamente, que "el asunto de la distribución de la riqueza es demasiado importante como para dejarlo en manos

1. Esto confirmaría lo que dije hace tiempo, tomando una distinción de la Política, de Aristóteles: hoy en nuestras escuelas ya no se enseña economía (el arte de administrar lo que hay), sino crematística (el arte de enriquecerse individualmente). Ver $E l$ amor en tiempos de cólera ... económica (Madrid, 2013, 38). 
de los economistas" (16). Y sostiene que nosotros tenemos hoy ventaja sobre los economistas anteriores, porque disponemos de un campo de investigación más amplio, que es toda la documentación de nuestra historia pasada.

Estas observaciones le sirven para dar un severo toque de atención a la orientación meramente matemática de las economías norteamericanas: tras confesarse seducido de joven por el "sueño americano" (a raíz de una oferta de trabajo recibida con motivo de su tesis doctoral), reconoce después su desengaño ante las ciencias económicas de aquel país, en unas líneas que no tienen desperdicio:

La disciplina económica no ha abandonado su pasión infantil por las matemáticas y las especulaciones puramente teóricas y a menudo muy ideológicas, en detrimento de la investigación histórica y de la reconciliación con las demás ciencias sociales. Con mucha frecuencia los economistas se preocupan ante todo por pequeños problemas matemáticos que sólo les interesan a ellos, lo que les permite darse, sin mucha dificultad, apariencias de cientificidad y les evita tener que contestar las preguntas mucho más complicadas que les hace la gente que los rodea ${ }^{2}$.

$\mathrm{Y}$ en otro momento:

No me gusta la expresión "ciencia económica"; me parece terriblemente arrogante y podría hacer creer que la economía ha logrado un estatuto científico superior, específico, distinto de las demás ciencias sociales [...] Modelos matemáticos que a menudo no son más que una excusa para ocupar terreno y disimular la vacuidad del objetivo (645-646).

Para que nadie se aterre ante esas afirmaciones y las etiquete antes de tiempo, aclaremos que Piketty no es ningún socialista, ni militante de mayo del 68. Cuando cayó la URSS tenía solo diecinueve años y no ha conocido otro sistema que el capitalismo. Ello no le impide reconocer que este tiene una tendencia casi imparable a producir desigualdades y a aumentarlas (algo que ya había reconocido el mismo Keynes, hace casi cien años). En este sentido, "en muchos aspectos el análisis marxista conserva cierta pertinencia"3.

La tesis del libro cabe en las siguientes palabras con las que casi se abre:

Cuando la tasa de rendimiento del capital supera de modo constante la tasa de crecimiento de la producción y del ingreso (lo que sucedía hasta el s. XIX y amenaza con volverse la norma del s. XXI), el capitalismo produce mecánicamente desigualdades insostenibles, arbitrarias que cuestionan de

2. P. 47, subrayados míos.

3. P. 24. Ver también: "la acumulación se detiene en un punto finito; pero este punto puede ser sumamente elevado y desestabilizador" (36). 
modo radical los valores [...] en los que se fundamentan nuestras sociedades democráticas ${ }^{4}$.

De acuerdo con eso, el capitalismo sería, a la larga, incompatible con la democracia (puesto que destroza sus valores), al revés de lo que repiten obstinadamente tantos economistas estadounidenses. Ello obliga a buscar si hay alguna forma de evitar esa contradicción, dado que "no tenemos ninguna razón para creer en el carácter autoequilibrado del crecimiento" (30), y las predicciones de algunos economistas favorables a ese equilibrio del mercado (por ascenso del capital humano, crecimiento de la educación...) "son en gran medida ilusiones" (36).

Para obtener un diagnóstico que permita recetar algún remedio, la obra de Piketty analiza tres factores:

- La dinámica de la distribución de las riquezas a escala mundial (Parte I).

- La dinámica de la relación capital-ingreso y del reparto entre capital y trabajo (Parte II).

- Y finalmente, la evolución de las desigualdades en los ingresos y en la riqueza (Parte III).

La primera parte se lleva dos capítulos del libro, la segunda cuatro y la tercera seis. Todas llevarán a una cuarta parte que busca cómo regular el capital en el siglo XXI, tras haber comprendido "de manera un poco más clara lo que serán las decisiones y las dinámicas operantes en el siglo que se inicia" (50).

El balance de estos análisis será que "las desigualdades patrimoniales mundiales, hoy en día crecen a un ritmo insostenible" (644). Son "fuerzas de divergencia amenazadoras para nuestras sociedades democráticas y para los valores de justicia social en que están basadas" (643). O con otras palabras: "una vez constituido, el capital se reproduce solo, más rápidamente de lo que crece la producción: el pasado devora al porvenir" (643).

Factor novedoso en sus análisis (para mí, al menos) es el tema de la herencia. Contra lo que sostienen algunos, el aumento de la concentración actual del capital no deriva de la prolongación de los años de vida y de la posibilidad de ahorrar más, sino de esa superioridad de la tasa de rendimiento del capital sobre la tasa de crecimiento del PIB, que muestra el libro. Esto hace que el tema de la herencia vuelva a ser, a comienzos del siglo XXI, tan importante como en el siglo XVIII, y en las novelas de Balzac o Jane Austen, varias veces citadas por Piketty. Seguramente, en el siglo XXI habrá más rentistas medianos y menos rentistas

4. P. 15, subrayado mío. El original dice "valores meritocráticos", palabra malsonante para un teólogo, porque le suena a fariseísmo. Pero en Piketty la meritocracia se contrapone al que se enriquece sin dar casi ni golpe. No hay que olvidar este significado, porque el autor usa con frecuencia esa palabra. 
enormes que en el siglo XVIII; habrá también sueldos de súper ejecutivos, antaño desconocidos. Pero ninguna de estas dos variaciones solucionará el problema de la desigualdad.

La solución - la única solución posible a esta amenaza - es un impuesto progresivo anual sobre el capital. No se trata de imponer gravámenes al rendimiento del capital - porque esto podría apagar el motor del crecimiento-, sino al capital mismo, lo cual además evitaría que este permanezca inactivo. Solo eso "permitiría contener el crecimiento sin límites de las desigualdades patrimoniales mundiales que hoy en día crecen a un ritmo insostenible a largo plazo" (644).

Dos conclusiones sugiere su reflexión sobre la herencia: a) "la democracia real y la justicia social exigen instituciones específicas propias, que no son simplemente las del mercado y que tampoco pueden reducirse a las instituciones parlamentarias y democráticas". Y b) "La idea conforme a la cual la libre competencia permite poner fin a la sociedad de la herencia y llegar a un mundo cada vez más meritocrático es una ilusión peligrosa" (466). Estas dos tesis son muy importantes: porque están en consonancia con todo el enfoque del libro sobre la necesidad de controlar al capital, y porque parece que nos encaminamos a una época en que volverá a crecer la herencia, primero en Europa y luego, aunque más lentamente, a nivel mundial ${ }^{5}$.

Solo tres rápidas observaciones para concluir la presentación de esta obra. La primera es que Piketty ha dado con un método de trabajo novedoso que es el estudio de las declaraciones de renta. Ello le hace ceñirse demasiado a Francia (aunque me confirman que tiene equipos en muchos países del mundo). Y permite también sospechar que sus análisis se quedan cortos, pues las declaraciones de renta de los más ricos son todas falsas, por defecto. En segundo lugar, echo de menos una mayor atención a los medios de comunicación y a la ecología. Los primeros porque son hoy el gran "poder fáctico", que sostiene al capital. Y lo segundo porque es quizás el gran peligro al que nos está llevando el desmadre del capital.

Finalmente, también llama la atención la serenidad con que el autor, a la vez que propone su solución y la concreta con ejemplos en dosis moderadas, dé por seguro que no será aceptada hoy. Puede reforzar esa suposición la cantidad de veces que Piketty constata en el libri que, a lo largo de la historia, las únicas correcciones al desmadre del capital y de las desigualdades tuvieron lugar en la primera mitad del siglo XX, con las dos guerras mundiales. Ello suscita una inevitable pregunta: si Piketty tiene razón, ¿a dónde nos encaminamos, pues?

5. El autor dice solo que "parece", porque los datos del resto de Europa y de Estados Unidos no son tan abundantes como los de Francia. Pero sí que apuntan en la misma dirección. 
Termino con una rápida panorámica sobre las reacciones al libro. Dejando estar todos los aplausos de autores como Krugman, apuntaré dos críticas, una por cada lado. Un economista peruano (H. de Soto) ${ }^{6}$ le acusa de desconocer que lo que el tercer mundo "realmente desea es más capital, no menos". Y critica la metodología de Piketty por analizar sobre todo países primermundistas. Pero no veo que esta crítica afecte al libro de Piketty. Todos están de acuerdo en que el tercer mundo necesita capital, pero quedan dos preguntas. La primera es por qué no lo tiene. ¿No parece ser la tendencia monopolista del capital, lo que priva al tercer mundo de ese motor de arranque? ¿O ella, junto a las exigencias del FMI (criticadas por Piketty) de desinvertir en sanidad y educación para prestar algún capital? La otra pregunta es si se trata de un capital que crea riqueza o que rinda más de la riqueza que se cree, porque en este otro caso volveremos al esquema de unos pocos muy ricos y muchos miserables. Y en el tercer mundo, más.

Por el otro lado y alabando mucho su metodología, un economista de izquierdas considera inocuo y casi falsificador al libro de Piketty ${ }^{7}$. El capital no es simplemente la fortuna obscena de los ricos, sino "un modo de producción y, por eso, no tiene derecho Piketty a apropiarse del título de la obra de Marx (que reconoce no haber leído). Pero otra vez, la desautorización me parece desenfocada. Piketty no ha titulado su obra como la de Marx, sino que añade: el capital "en el siglo XXI". Eso nos orienta más hacia una pretensión más modesta que la de Marx; y en vez de mirarlo casi como un falsificador, se le podría mirar como un precursor: si el capital tiene esa tendencia científicamente cierta hacia una concentración obscena, habrá que procurar descubrir cuáles son las causas de esa dinámica. Y eso daría pie a todo lo que esta crítica anhela.

No veo, pues, motivos para desautorizar este libro: otra cosa será reconocer que no es una última palabra. Pero eso pasa con todos los pasos adelante que da la ciencia. Desde mi óptica personal, lo que más plantea el libro de Piketty es la necesidad de establecer un verdadero diálogo y confrontación entre economía y teología: si la economía es una ciencia humana y si su objetivo son las desigualdades y la igualdad entre los hombres, ambas cosas pueden definir también a la teología, aunque desde ángulos diversos.

6. H. de Soto, "Los pobres frente a Piketty", El País, 3 de mayo de 2015, pp. 6-7.

7. F. Lordon, "Con Thomas Piketty no hay peligro para el capital en el siglo XX", Le Monde Diplomatique, abril 2015, pp. 20-21. Lordon es autor de otro libro, contemporáneo del de Piketty, La malfaçon. Monnaie européene et souveranité democratique. 